\title{
Mobility of sedentary older: benefit from an adapted physical activity program
}

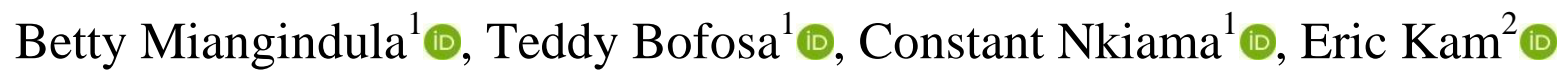 \\ ${ }^{1}$ Department of Physical Medicine and Rehabilitation, Kinesiology Service, University Clinics of Kinshasa, Faculty of Medicine, \\ University of Kinshasa, Democratic Republic of Congo. ${ }^{2}$ Department of Physical Medicine and Rehabilitation, Adult Neuro- \\ Rehabilitation Unit, University Clinics of Kinshasa, Faculty of Medicine, University of Kinshasa, Democratic Republic of Congo.
}

Abstract. This study aimed to assess the impact of an adapted physical activity program on the motor capacity of elderly people with reduced mobility. A total of 65 elderly subjects living in an institution divided into 2 groups according to sex and age, selected occasionally, were subjected to an adapted physical activity program over a period of 3 months. We checked the effects of this program at the end on joint flexibility of the back, static and dynamic balance, general dynamic coordination or endurance. This study showed that the static balance of men and women improved significantly, respectively, $15.8 \pm 6.96$ vs. $17.57 \pm 4.65 \mathrm{sec} ; 13.15 \pm$ 2.45 vs. $15.28 \pm 1.72 \mathrm{sec}$. Regarding the influence of age, we observed that subjects aged 70-75 improved their flexibility $(6.18 \pm 5.04 \mathrm{~cm}$ vs. $4.87 \pm 4.08 \mathrm{~cm} ; p<$ $.05)$, their static balance (10.56 $\pm 6.27 \mathrm{sec}$ vs. $13.53 \pm$ $5.91 \mathrm{sec} ; p<.05)$ and their dynamic equilibrium $(16.42 \pm 3.32$ sec vs. $14.35 \pm 3.21 ; p<.05)$. On the other hand, those whose age varies between 76 and 81 years old only improved their static balance $(12.62 \pm 8.2 \mathrm{sec}$ vs. $14.13 \pm 8.52 \mathrm{sec} ; p<.05)$. Men significantly increased their distance on the 6 Minute Walk Test (6MWT; $166 \pm 52 \mathrm{~m}$ vs. $180 \pm 45.3$ $\mathrm{m} ; p<.05)$ and $\mathrm{VO}_{2} \max (16.22 \pm 0.86$ vs. $16.75 \pm 0.99$ $\mathrm{ml} / \mathrm{kg} / \mathrm{min} ; p<.05)$ while the women only increased their distance on 6MWT $(136 \pm 30.9 \mathrm{~m}$ vs. $159 \pm 48.95 \mathrm{~m} ; p<.05)$. Subjects aged $<75$ years improved after the program their speed $(0.66 \pm 0.209$ $\mathrm{m} / \mathrm{sec}$ vs. $0.69 \pm 0.206 \mathrm{~m} / \mathrm{sec} ; p<.05)$ and their distance on 6MWT $(169.93 \pm 59.7 \mathrm{~m}$ vs. $193.87 \pm 58.3$ $\mathrm{m} ; \mathrm{p}<.05)$. This study reveals that the exercise retraining program allows older people to improve their mobility (joint flexibility of the back, static and dynamic balance, general dynamic coordination and endurance). However, these benefits depend on the age and sex of the subject.

Keywords. Adapted physical activity, elderly people, mobility, sedentary.

\section{Introduction}

The world's population is aging, and the Democratic Republic of Congo (DRC) is no exception. This is due, among other things, to the concern that individuals have in their own health. However, aging, which is a natural and inevitable phenomenon, is systematically accompanied by a progressive decrease in the functional capacities of the organism, modifications which appear most often in situations which bring into play the functional reserves as during 'an effort, or with the onset of an acute illness. The body is then no longer able to adapt properly and cope with different situations of genetic or environmental attacks (Bofosa et al., 2019; Ding et al., 2017).

Mobility of the elderly is defined as the ability of subjects to move from one point to another independently and safely. This ability to move can be impaired by a sedentary lifestyle (Clement, 2018).

According to the World Health Organization, physical inactivity is the fourth most common risk factor for mortality worldwide, just after hypertension, smoking 
and diabetes (Cameron, 2012; Means et al., 2015; Salma et al., 2010). The level of inactivity is increasing in many countries with major consequences on the general health of the population, in particular the onset with age of non-communicable diseases such as cardiovascular disease, diabetes, cancer, arterial hypertension (Karssemeijer et al., 2017; Jiménez \& Fernander, 2016). It is necessary to encourage the elderly to avoid this sedentary life and to see retirement as an opportunity to gain new habits and to devote time to physical activity (Pillar, 2017; Giaccardi \& Lassel, 2015; Sherrington et al., 2019).

In this context, several associations offer awareness, information and training programs in APA and reflect on the means to be implemented to get as many seniors as possible to join so that these activities can be sustained over time (Hopewell et al., 2018; Puts et al., 2017). In this vein, the associations created in the hospices offer seniors courses in maintenance gymnastics, balance, fall prevention, walking, aqua gym and other activities according to their desire and needs (Bigot, 2017; Fournier, 2012).

In the DRC, the problem arises in the opposite terms. Indeed, we have seen that people living in our hospices are faced with an increased sedentary lifestyle; physical activity is neither present nor prescribed in the preventive context or even in the curative context of the health of seniors; very few of them benefit from physiotherapy care and it is on an ad hoc basis; the lack of information and training on physical activity or of a workshop offering advice on how to learn to move more; impaired mobility with risk of fracture and disability. These people become incapacitated and lock themselves into a routine leading to deconditioning, immobility and addiction

This study aimed to assess the impact of an adapted physical activity program on the motor capacity of elderly people with reduced mobility.

\section{Methods}

This study was carried out in two different Hospices: that of the Municipality of Kimbanseke, "Saint-Marc" and that of the Municipality of Kinshasa, "Saint-Pierre". The choice of these two institutions is justified, among other things, by the need to gather a good sample and by the conditions of accessibility or acceptability that we have not found elsewhere.

This is a cross-sectional and experimental study through which we initially collected data related to the mobility of elderly people living in institutions, they then administered the adapted physical activity program and we evaluated in the end, its impact on joint flexibility of the back, static and dynamic balance, general dynamic coordination or endurance. This study covered a 3-month period from October 2019 to January 2020.

This study was conducted in accordance with the rules of ethics and the methodology was approved by the Ethics Committee of the School of Public Health of the University of Kinshasa (ESP / CE / 0010/2019. All participants signed a consent allowing their participation under the Helsinki Declarations.

\section{Sample}

In total, we selected 65 elderly subjects divided into 2 groups according to sex, including 35 women (20 in Saint-Pierre and 15 in SaintMarc) and 30 men (20 in Saint-Pierre and 10 in Saint-Marc) and depending on age $<75$ years ( $n$ $=34)$ and $\geq 75$ years $(n=31)$. These participants were selected from time to time, according to a few previously established criteria.

Inclusion criteria: To be included in this study, the following conditions had to be met: Be housed at the Saint-Marc or Saint-Pierre hospice; be a person aged 65 to 85 years; Agree to participate freely in the study.

Exclusion criteria: The following were excluded from this study: All those who did not 
understand the instructions; all of those who did not meet the above inclusion criteria.

\section{Data Collection}

We measured the following parameters: 1) Anthropometric parameters, 2) Mobility parameters. These two parameters evaluated by physiotherapists and kinesiologists, allowed us to have an idea on the morphological state and mobility of the elderly in order to verify the influence of an adapted physical activity program on these parameters.

\section{Anthropometric parameters}

Weight $(\mathrm{kg})$ :The measurement of the weight allowed us to have an idea on the weight status of the elderly, but also for the calculation of the body mass index (BMI). It was measured on the basis of the SECA brand balance calibrated in kilogram (kg) with an accuracy of $100 \mathrm{mg}$; the subject standing, barefoot and lightly dressed.

Height $(\mathrm{cm})$ : The height measurement helped us to calculate the body mass index. It was taken using a SECA mark, mounted on a vertical scale, the subject standing, barefoot and having removed any ornament (hat, kepi, etc.) from the head. The measuring rod slides vertically on the supporting branch of the measuring rod to the top of the head. The body mass index was calculated using the following formula: $\mathrm{BMI}=$ weight $/$ height $(\mathrm{m})^{2}$.

Mobility parameters: A total of 5 tests were used to measure the mobility of the elderly in this study: flexibility; Static balance; dynamic balance; speed; the Six-Minutes Walk Test (6MWT).

Flexibility (cm) (Shöber test): The subject is placed on a bench, feet together. It consisted in asking the subject to make an anterior projection of the trunk while trying, with the pointed hands on the ground, to go beyond the feet without bending his knees. The measurement with a ruler begins where the middle fingers are. If the middle fingers do not reach the toes, the test is negative; if they reach, the test is " 0 "; if they go beyond the toes, the test is positive. The Shöber is recorded in centimeters with an accuracy of $0.1 \mathrm{~cm}$. Static balance (unipodal support test): it consisted in asking the subject to stay on one foot as long as possible. The measurement is taken in seconds using a stopwatch. Quotation: Value greater than 5 seconds (without help) = normal; Value greater than 5 seconds (with balancing difficulties) $=$ adapted response; Value less than 5 seconds $=$ risk of serious falls (fractures)

Dynamic balance (Timed up and Go test): It consisted in asking the subject to get up from his chair, travel 3 meters back and forth, to come back to sit on the chair. Time is timed in seconds. For the test, 1 chair with armrest, a corridor, a cone, 1 notepad and a stopwatch were used. Quotation: 1) Value less than 10 seconds = completely independent, 2) Value between 10 and 19 seconds $=$ no serious mobility problems, 3) Value between 20 and 29 seconds = average mobility, 4) Value greater than 30 seconds $=$ physically dependent .

Speed (walking speed test): It consisted in asking the subject to walk as fast as he could, without running, on a trajectory of 4 meters. The measurement is taken in meters per second $(\mathrm{m} / \mathrm{s})$. The speed was calculated by the following formula: $\mathrm{V}=$ Distance $(\mathrm{m}) /$ Time (sec). Quotation: 1) Value greater than $0.80 \mathrm{~m} / \mathrm{s}$ $=$ normal, 2) Value greater than $1.0 \mathrm{~m} / \mathrm{s}=\operatorname{good}$ security, good vital and functional prognosis, 3) Value less than $1.0 \mathrm{~m} / \mathrm{s}=$ cognitive decline within 5 years, 4) Value less than $0.8 \mathrm{~m} / \mathrm{s}=$ motor dependence, 5) Value less than $0.7 \mathrm{~m} / \mathrm{s}=$ death, falls, hospitalization, 6) Value less than $0.6 \mathrm{~m} \mathrm{~s}=$ cognitive, functional decline, institutionalization, death, 7) Value less than $0.15 \mathrm{~m} / \mathrm{s}=$ very dependent.

Adaptation to effort (Six-minute walk test): It consisted in asking the subject to walk (and not run) for six minutes on a 15-meter trajectory. Time is timed and the number of laps is counted. The distance is recorded in meters. The $\mathrm{VO}_{2} \max$ was calculated by the following 
formula (Du et al., 2018): $\mathrm{VO}_{2} \max (\mathrm{ml} / \mathrm{kg} / \mathrm{min})$ $=0.1 \times($ distance $/$ time $)+3.5$.

\section{Description of the Adapted Physical Activity Program}

General objectives of the program is to improve the mobility capacity of the elderly through an adapted physical activity program by working muscle function, balance capacity, aerobic capacity, flexibility and coordination.

Specific objectives: 1) Work on muscle function through segmental strengthening exercises, more specifically of the lower limbs, 2) Exercise the capacity of balance in static and dynamic, 3) Work on joint flexibility through mobilization and stretching exercises, 4) Work on aerobic capacity in order to slightly improve the maximum oxygen consumption ( $\left.\mathrm{VO}_{2} \mathrm{max}\right)$.

The program, which lasted between 20 and 45 minutes, was applied twice a week for 12 weeks in participants' houses. The program consisted of muscular strengthening, balance, flexibility and aerobic gymnastics. These activities were led by physiotherapists and kinesiologists. Measurements were taken twice before and after the program. The following tests have been performed: Six-minute walk test (6MWT), Timed up and go test (TUG), $4 \mathrm{~m}$ walk speed test, Unipodal support and Shober.

\section{Data Analyses}

The data analyzed by using the SPSS 21.0 (Statistical Package for Social Sciences). The subjects were divided according to: from the whole group; sex: man and woman and age: $<75$ years old and $\geq 75$ years old. The parametric student $t$ test was used to compare the mean values from the first and second handover. To check the effects of the program, we compared the before and after results of men and women. The results of the statistical tests used are interpreted at the significance level of $0.5 \%$ for a statistical decision.

\section{Results}

Table 1 shows that there were no statistical modifications of morphological parameters after the intervention program.

Table 2 revealed that the men have modified their static balance, speed, distance in six meter walk test and $\mathrm{VO}_{2}$ max while women have modified only their static balance and distance in 6MWT.

It can be seen from Table 2 that after the intervention program, the elder people of $<75$ years have modified their flexibility, static and dynamic balance, speed and distance in six meter walk test. The elder people of $\geq 75$ years have modified only their static balance.

\begin{tabular}{|c|c|c|c|c|}
\hline Groups & Parameters & Before & After & $p$ \\
\hline \multirow{2}{*}{ Male $(n=30)$} & Weight (kg) & $59.14 \pm 7.47$ & $58.8 \pm 7.47$ & 0.532 \\
\hline & BMI $\left(\mathrm{kg} / \mathrm{m}^{2}\right)$ & $24.05 \pm 2.3$ & $23.8 \pm 2.13$ & 0.971 \\
\hline \multirow{2}{*}{ Female $(n=35)$} & Weight (kg) & $54.05 \pm 12.66$ & $53.66 \pm 12.05$ & 0.33 \\
\hline & BMI $\left(\mathrm{kg} / \mathrm{m}^{2}\right)$ & $24.23 \pm 4.75$ & $24.0 \pm 4.44$ & 0.826 \\
\hline \multirow{2}{*}{$<75$ years $(n=34)$} & Weight (kg) & $59.62 \pm 10.41$ & $59.06 \pm 10.08$ & 0.549 \\
\hline & BMI $\left(\mathrm{kg} / \mathrm{m}^{2}\right)$ & $25.18 \pm 3.59$ & $24.86 \pm 3.26$ & 0.501 \\
\hline \multirow{2}{*}{$\geq 75$ years $(n=31)$} & Weight (kg) & $52.93 \pm 10.56$ & $52.75 \pm 10.05$ & 0.061 \\
\hline & $\mathrm{BMI}\left(\mathrm{kg} / \mathrm{m}^{2}\right)$ & $23.12 \pm 3.87$ & $22.98 \pm 3.71$ & 0.09 \\
\hline
\end{tabular}


Table 2

Comparison of mobility parameters of men and women before and after the program.

\begin{tabular}{|c|c|c|c|c|}
\hline Groups & Parameters & Before & After & $p$ \\
\hline \multirow[t]{6}{*}{ Men $(n=30)$} & Flexibility $(\mathrm{cm})$ & $3.25 \pm 0.84$ & $2.12 \pm 0.21$ & 0.06 \\
\hline & Static Balance (sec) & $15.8 \pm 6.96$ & $17.57 \pm 4.65$ & $0.021 *$ \\
\hline & Dynamic Balance (sec) & $15.15 \pm 2.44$ & $12.7 \pm 4.2$ & 0.073 \\
\hline & Speed (m/sec) & $0.66 \pm 0.28$ & $0.68 \pm 0.3$ & $0.001 *$ \\
\hline & $6 \mathrm{MWT}(\mathrm{m})$ & $166 \pm 52$ & $180 \pm 45.3$ & $0.025^{*}$ \\
\hline & $\mathrm{VO}_{2} \max (\mathrm{ml} / \mathrm{kg} / \mathrm{min})$ & $41.22 \pm 0.86$ & $45.75 \pm 0.99$ & $0.002 *$ \\
\hline \multirow[t]{6}{*}{ Women $(n=35)$} & Flexibility $(\mathrm{cm})$ & $4.81 \pm 1.04$ & $3.22 \pm 1.5$ & 0.762 \\
\hline & Static Balance (sec) & $13.15 \pm 2.45$ & $15.28 \pm 1.72$ & $0.007^{*}$ \\
\hline & Dynamic Balance (sec) & $17.02 \pm 3.15$ & $15.9 \pm 4$ & 0.063 \\
\hline & Speed (m/sec) & $0.53 \pm 0.23$ & $0.54 \pm 0.23$ & 0.075 \\
\hline & 6MWT (m) & $136 \pm 30.9$ & $159 \pm 48.95$ & $0.03^{*}$ \\
\hline & $\mathrm{VO}_{2} \max (\mathrm{ml} / \mathrm{kg} / \mathrm{min})$ & $38.8 \pm 0.5$ & $40.1 \pm 0.8$ & 0.452 \\
\hline
\end{tabular}

Table 3

Comparison of mobility parameters of the elder people according to age.

\begin{tabular}{llccc}
\hline Group & Parameters & Before & After & $p$ \\
\hline$<75$ years $(\mathrm{n}=34)$ & Flexibility $(\mathrm{cm})$ & $6.18 \pm 5.04$ & $4.87 \pm 4.08$ & $0.05^{*}$ \\
& Static Balance $(\mathrm{sec})$ & $10.56 \pm 6.27$ & $13.53 \pm 5.91$ & $0.004^{*}$ \\
& Dynamic Balance $(\mathrm{sec})$ & $16.42 \pm 3.32$ & $14.35 \pm 3.21$ & $0.005^{*}$ \\
& Speed $(\mathrm{m} / \mathrm{sec})$ & $0.66 \pm 0.21$ & $0.69 \pm 0.21$ & $0.0001^{*}$ \\
& $6 \mathrm{MWT}(\mathrm{m})$ & $169.93 \pm 59.7$ & $193.87 \pm 58.3$ & $0.006^{*}$ \\
& VO ${ }_{2} \max (\mathrm{ml} / \mathrm{kg} / \mathrm{min})$ & $42.96 \pm 1.42$ & $44.5 \pm 1.27$ & 0.8 \\
& Flexibility $(\mathrm{cm})$ & $2.12 \pm 0.12$ & $1.68 \pm 0.64$ & 0.174 \\
& Static Balance $(\mathrm{sec})$ & $12.62 \pm 8.2$ & $14.13 \pm 8.52$ & $0.03^{*}$ \\
& Dynamic Balance $(\mathrm{sec})$ & $17.48 \pm 4.29$ & $15.58 \pm 5.07$ & 0.83 \\
& Speed $(\mathrm{m} / \mathrm{sec})$ & $0.57 \pm 0.19$ & $0.59 \pm 0.2$ & 0.14 \\
& $6 \mathrm{MWT}(\mathrm{m})$ & $198.92 \pm 88.4$ & $214.4 \pm 83.5$ & 0.083 \\
& VO $(\mathrm{n}=31)$ & $37.98 \pm 0.69$ & $39.42 \pm 9.08$ & 0.12 \\
\hline$* 0.05$ & & & & \\
& & &
\end{tabular}

\section{Discussion}

This is an experimental method and we conducted a cross-sectional study through which we initially collected data related to the mobility of the elderly. We then administered the exercise retraining program and ultimately assessed its impact on the parameters measured.

Barret et al. (2015) point out that the regular practice of physical activities leads to significant energy expenditure, causing significant weight loss. These results differ from our one, which shows no significant improvement in weight and body mass index in elderly subjects after the intervention program. This could be justified by the fact that our study duration was shorter.

Our results corroborate those found by Thelot et al. (2017) who worked on the impact of an adapted physical activity program on the quality of life and physiological characteristics 
of elderly people and showed that As a result of an ABA program proposed in his study, body mass was not changed.

Du et al. (2018) have shown that the unipodal test is a good way to identify the nonfallers of the fallers since the latter are unable to hold this position for 30 seconds. On unipodal tests of six times on average and four times respectively for the condition "eyes open" and of 2.5 times and twice on average respectively for the condition "eyes closed". Through training, Hoffmann et al. (2016) showed that fallers and non-fallers significantly increased their static balance. In our study, we also evaluated static balance and observed its significant change after the 12-week exercise retraining program in the whole group (Hoffmann et al., 2016).

Regarding the influence of gender in men and women our study showed that the practice of exercise retraining has a significant influence only on static balance in both sexes. These results differ from those of Clement (2018) who showed that the amount of physical activity therefore has an influence on men's performance but not on that of women. These differences in results are justified by the fact that our sample, being 16 subjects, did not allow us to perceive inter-sex differences compared to the study conducted by Primault (2018) which was conducted with a sample of 500 elderly participants.

Regarding the influence of age, we observed in this study that younger subjects significantly improved their flexibility, static and dynamic balance, while older subjects only changed their static balance. With age associated with the decline in sensory function and muscle strength in the lower limbs, Hoffmann et al. (2016) have shown an influence of age on flexibility, static and dynamic balance. They pointed out that the older the more the average values of these reduced parameters advance.

Indeed, many studies in frail people aged 80 years on average have shown the effectiveness of an exercise re-training program based on muscle strengthening in improving general dynamic coordination and cardiorespiratory endurance (Bofosa et al., 2018; Riou, 2014).

However, it emerges from this study that the exercise re-training program has a significant influence on the general dynamic coordination (speed) and cardiorespiratory endurance $\left(\mathrm{VO}_{2} \max \right)$ of elderly subjects as a whole.Studies of intervention programs show that older people can improve their cardiorespiratory capacity because they have the ability to adapt to physical training.

Regarding the influence of gender on general dynamic coordination (speed) and cardiorespiratory endurance $\left(\mathrm{VO}_{2} \mathrm{max}\right)$ of older subjects, we observed that men significantly improved their speed and $\mathrm{VO}_{2}$ max compared to women.

Pillard et al. (2017) have shown that the practice of physical activities allows a significant improvement in general dynamic coordination and cardiorespiratory endurance in elderly subjects.Regarding the effect of age, we noticed that younger subjects had a very significant change in their general dynamic coordination (speed) and cardiorespiratory endurance $\left(\mathrm{VO}_{2} \max \right)$ compared to older subjects.

These results corroborate those in the literature which underline that the gain of practicing an exercise re-training program is a function of the subject's age. The older the age, the less and less the efforts of physical activity are perceived (Clement, 2018).

Since our study sample was small, our conclusions relate only to elderly subjects who took part in this study.

\section{Conclusion}

Regular practice of adapted physical activities allows elderly people living in institutions to improve their mobility regardless of gender and age. We suggest that an adapted physical activity program be introduced in the care of the elderly. 


\section{Funding}

The authors received no financial support for the research.

\section{Conflict of Interests}

Authors have declared that no competing interest exists.

\section{References}

Barret, S., Demouge, L., Pillard, F., Lapeyre-Mestre, M., \& Rolland, Y. (2015). Exercise training for managing behavioral and psychological symptoms in people with dementia: a systematic review and meta-analysis. Ageing Res Rev, 24(6): 27-33.

Bofosa, T., Kam, E., Miangindula, B., Njimbu, F., \& Nkiama, C. (2018). Improvement of the cardiorespiratory endurance, perception of the effort and walking performance of the old people of the hospice Saint Marc of Kingasani by the practice of the adapted physical activities. European Res J, 6, 211-216.

Bofosa, T., Kam, E., Miangindula, B., Njimbu, F., Nkiama, C., Kiana N., \& Muela, D. (2019). Fall and quality of life of the elderly: effect of a physical exercise program focused on the balance training. International Journal of Aging Health and Movement, 1(1): 1-10.

Cameron, I.D., Gillespie, L.D., Robertson, M.C., Murray, G.R., Hill, K.D., \& Cumming, R.G. (2012). Interventions for preventing falls in older people in care facilities and hospitals. The Cochrane Database of Systematic Reviews, 12, 71-76.

Clement, P. (2018). The balance evaluation systems test (BESTest) to differentiate balance deficits. PhysTher, 89, 484-498.

Ding, Y.Y., Kuha, J., \& Murphy, M. (2017). Pathways from physical frailty to activity limitation in older people: Identifying moderators and mediators in the English longitudinal study of ageing. Exp Gerontol, 98, 169-176.

Du, Z., Li, Y., Li, J., Zhou, C., Li, F., \&Yang, X. (2018). Physical activity can improve cognition in patients with Alzheimer's disease: a systematic review and meta-analysis of randomized controlled trials. Clin Interv Aging, 13, 1593-1603.
Faber, M.J., Bosscher, R.J., Chin, M.J., \& Van Wieringen, P.C. (2006). Effects of exercise programs on falls and mobility in frail and prefrail older adults : a multicenter randomized controlled trial. Arch Phys Med Rehabil, 87, 885896.

Fournier, J., Vuillemin, A., Le Cren, F. (2012). Measuring physical fitness in the elderly. assessment of physical fitness in elderly: French adaptation of the "Senior Fitness Test". Science $\mathcal{E}$ Sports, 27(4), 254-259.

Giaccardi, Y., \& Laassel, M. (2015). Evaluation of the risk of falling in EHPAD by GAITRite walking track. 3rd Annual Meeting of FFAMCO, 19 May 2015.

Jimenez, G.G., \& Fernández, N.P. (2016). Reduction in posterior semicircular gain by age in video head impulse testing: observational study. Acta Otorrinolaringol Esp, 67, 15-22.

Hopewell, S., Adedire, O., Copsey, B.J., Boniface, G.J., Sherrington, C., \& Clemson, L. (2018). Multifactorial and multiple component interventions for preventing falls in older people living in the community. The Cochrane Database of Systematic Reviews, 7, 33-40.

Karssemeijer, E.G.A., Aaronson, J.A., Bossers, W.J., Smits, T., Olde Rikkert, M.G.M., \& Kessels, R.P.C. (2017). Positive effects of combined cognitive and physical exercise training on cognitive function in older adults with mild cognitive impairment or dementia: ametaanalysis. Ageing Res Rev, 40, 75-83.

Hoffmann, K., Sobol, N.A., Frederiksen, K.S., Beyer, N., Vogel, A., Vestergaard, K., et al. (2016). Moderate-to-high intensity physical exercise in patients with Alzheimer's disease: a randomized controlled trial. J Alzheimers Dis, 50(2), 443-453.

Means, K.M., Rodell, D.E., \& O'sullivan, P.S. (2015). Balance, mobility, and falls among communitydwelling elderly persons: effects of a rehabilitation exercise program. Am J PhysMed Rehabil, 84, 238-250.

Puts, M.T.E., Toubasi, S., Andrew, M.K., Ashe, M.C., Ploeg, J., \& Atkinson, E. (2017). Interventions to prevent or reduce the level of frailty in community-dwelling older adults: a scoping review of the literature and international policies. Age Ageing, 46(3), 383-392. 
Pillar, F., Li, G., Hua, S., Liu, Y., \& Chen, L. (2017). Effect of exercise on cognitive function in chronic disease patients: a meta-analysis and systematic review of randomized controlled trials. Clin Interv Aging, 12, 773-783.

Riou, J.-M. (2014). Test de marche de 6 minutes en pratique. Physical Fitness in assessment Manuel.

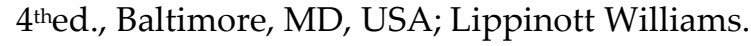

Salma, S.S., Coelho, F.G.M., Gobbi, S., \& Stella, F. (2010). Effects of physical activity on cognitive functions, balance and risk of falls in elderly patients with Alzheimer's dementia. Rev Bras Fisioter, 14, 68-74.

Sherrington, C., Fairhall, N.J., Wallbank, G.K., Tiedemann, A., Michaleff, Z.A., \& Howard, K. (2019). Exercise for preventing falls in older people living in the community. The Cochrane Database of Systematic Reviews, 1, 45-51.

Thelot, B., Lasbeur, L., \& Pedrono, G. (2017). Epidemiological surveillance of falls in the elderly. Bull Epidémiol Hebdo, 16-17, 328-335. 